\title{
Paroxysmal movement disorders - practical update on diagnosis and management
}

Claudio M. de Gusmao, ${ }^{1,2}$, Laura Silveira-Moriyama, MD PhD², 3,4

\section{Affiliations:}

1.Department of Neurology, Boston Children's Hospital, Harvard Medical School, Boston, USA

2.Universidade Estadual de Campinas (UNICAMP), São Paulo, Brazil

3. Education Unit, UCL Institute of Neurology, University College London, London, UK

4. Hospital Bairral, Fundação Espírita Américo Bairral, Itapira, Brazil

\section{Corresponding author:}

Prof Laura Silveira Moriyama, Departamento de Neurologia, Faculdade de Ciências Médicas, Universidade Estadual de Campinas

Rua Tessália Vieira de Camargo, 126 - Cidade Universitária Zeferino Vaz. CEP 13083887 - Campinas, SP, Brasil

email: laura.moriyama@ucl.ac.uk

Funding details: This study was financed in part by the Coordenação de Aperfeiçoamento de Pessoal de Nível Superior - Brasil (CAPES) - Finance Code 001

Financial and competing interests disclosure: The authors report no sources of funding or conflicts of interest concerning the research related to this manuscript. Claudio Melo de Gusmao has received research funding from the National Ataxia Foundation. 


\section{Structured abstract}

Introduction: Paroxysmal dyskinesias and episodic ataxias are often caused by mutations in genes related to cell membrane and synaptic function. Despite the exponential increase in publications of genetically confirmed cases, management remains largely clinical based on non-systematic evidence.

Areas covered: We provide a historical and clinical review of the main types of paroxysmal dyskinesias and episodic ataxias, with recommendations for diagnosis and management of patients suffering from these conditions.

Expert opinion: After secondary paroxysmal dyskinesias, the most common paroxysmal movement disorders are likely to be PRRT2-associated paroxysmal kinesigenic dyskinesias, which respond well to small doses of carbamazepine, and episodic ataxia type 2, which often responds to acetazolamide. Familial paroxysmal non-kinesigenic dyskinesias are largely caused by mutations in PNKD and have poor response to therapy but improve with age. Exercise-induced dyskinesias are genetically heterogeneous, caused by disorders of glucose transport, mitochondrial function, dopaminergic pathways or neurodegenerative conditions amongst others. GNAO1 and ADCY 5 mutations can also cause paroxysmal movement disorders, often in the context of ongoing motor symptoms. Although a therapeutic trial is justified for classic cases and in limited resource settings, genetic testing may help direct initial or rescue therapy. Deep brain stimulation may be an option for severe cases. 
Keywords: acetazolamide, antiepileptic drugs, episodic ataxias, paroxysmal dyskinesias, paroxysmal movement disorders

\section{Article highlights}

- Paroxysmal movement disorders encompass episodic ataxia and paroxysmal dyskinesia (dystonia/chorea)

- Paroxysmal movement disorders may be caused by genetic mutations affecting cell membrane or synaptic function, or secondary to several types of structural abnormalities

- Clinical (phenotypic) diagnosis is mainly based on the type of movement abnormality and main triggers for the attacks.

- The main genes associated with paroxysmal movement disorders are PRRT2, PNKD, SLC2A1, CACNA1A, KCNA1, GCH1, PARKIN. These conditions have clinical overlap but respond to different treatments. Several other genetic causes have been described, including mitochondrial disorders, ATP1A3, GNAO1, $A D C Y 5$, among others.

- Genotype-phenotype correlations are complex and treatment can be directed by clinical or genetic diagnosis. 


\section{Introduction}

The concept of paroxysmal, or episodic disease manifestations, is not new to neurology. Several conditions have intermittent symptoms, with a normal or near-normal examination in-between: migraines, epileptic seizures and muscle channelopathies are examples of diseases that are well-known to the neurological audience. In movement disorders, these disorders have been grouped under their presenting symptom, namely dyskinesia (when there is dystonia and/or chorea) or ataxia (when there is a combination of cerebellar signs, including imbalance, dysarthria, nystagmus, truncal or appendicular incoordination). Historically, the terminology to indicate the intermittent nature of the movement abnormality has evolved designating "paroxysmal dyskinesias" for the former and "episodic ataxias" for the latter. Formally, the term paroxysmal confers meaning to a disorder occurring suddenly out of a normal motor background, but is not fundamentally different to the term "episodic". [1] The use of the "paroxysmal" and "episodic" is therefore arbitrary and interchangeable.

Although the initial concept involved a normal or near-normal intercritical neurological examination, mild intercritical signs were later incorporated as features to assist in the clinical characterization. Advances in neurogenetics allowed for the recognition of a wide spectrum of clinical features, ranging from severe presentations of classical episodic/paroxysmal disorders to newly described phenotypes with significant intercritical findings. These developments added to the complexity of nomenclature and understanding of these conditions.

Episodic involuntary movements may be present in various disorders including druginduced movement disorders, metabolic crisis in neurometabolic disorders, actionrelated dyskinesias in cerebral palsy, abnormal movements in cataplexy, levodopainduced dyskinesias in Parkinson's and so on. More recently, much attention has been paid to episodic dyskinesia as part of the spectrum of complex neurogenetic conditions such as neurodevelopmental conditions due to ATP1A3 and GNAO1, and to 
neurometabolic disorders including neurotransmitter diseases and mitochondrial disorders. Nevertheless, for the purpose of this review we have defined primary paroxysmal movement disorders as those previously described conditions in which the paroxysmal movement abnormality is considered the main hallmark of the disorder, and it is not secondary to structural or metabolic abnormality.

The heterogeneity of clinical features in genetically confirmed paroxysmal movement disorders, together with the increased number of genes associated with intermittent neurologic symptoms may leave clinicians baffled at the bedside. The dizzying array of disparate symptoms and causative mutations has led to the current notion that gene panels or extensive genetic sequencing is the method of choice for a precise nosologic diagnosis. Nevertheless, there is not yet a consensus in the literature whether genotype or phenotype should guide treatment. Therefore, the semiological knowledge of these conditions and their clinical manifestations is still paramount for patient management.

In this review we highlight classic and overlooked clinical features present in these conditions which can serve as diagnostic cues and also direct treatment. Various recent reviews have approached the expanding role of neurogenetics in the diagnosis of these conditions and we briefly summarize these advances, highlighting their correlation with management strategies whenever possible.

\section{Brief summary of historical aspects}

\subsection{Paroxysmal dyskinesias}

In 1892, Kure first reported on a teenage patient who, having had a normal previous developmental history, presented with spells of sudden muscular spasms that seemed to occur upon initiating movement. Taking advantage of recent developments in medical photography, he captured the patient's muscular spasms upon standing up from a chair. Since the manifestation was primarily related to muscular contraction, he interpreted the 
condition as being in the spectrum of a neuromuscular disorder, and called it atypical Thomsen's disease. [2] A decade later, Gowers called attention in his treatise on Epilepsy to attacks that could be triggered by voluntary motion. [3] It was not until 1940 that Mount and Reback, a resident and an attending working at the Neurological institute at Columbia in New York, described a family with sudden attacks and negative EEG, coining the term familial paroxysmal choreoathetosis. [4] Different from the former cases, in this family the spells seemed to be triggered by alcohol and fatigue. Other cases were described, occasionally emphasizing the presence of dystonia, in addition or separate from choreoathetosis. The distinction in triggering factors was sharpened by Kertesz, who in 1967 described several cases in which attacks were triggered by initiation of movement. In 1977, Lance[5] reviewed 112 cases classifying them primarily according to the phenomenology of attacks (dystonic choreoathetosis or only choreoathetosis), duration and triggers of attacks. He divided cases in categories: those with prolonged (minutes to hours) episodes in "paroxysmal dystonic choreoathetosis", brief (seconds to minutes) kinesigenic episodes in "paroxysmal kinesigenic choreoathetosis" or intermediate duration of attacks caused by exertion. In 1978, Goodenough[6] and colleagues added the notion that by etiology these conditions could be classified into familial and acquired. In 1994, Fahn [7] added "hypnogenic paroxysmal dyskinesia" (described in 1981 by Lugaresi and Cirignotta [8]), benign paroxysmal dystonia/torticollis in infancy, and a miscellaneous group.

In 1995 Dermikiran and Jankovic [9] proposed the classification and nomenclature which is still used nowadays, removing the phenomenology of attacks as a criteria for classification and substituting them for triggering factors. Categories included nonkinesigenic, kinesigenic, exercise-induced or hypnogenic (triggered by sleep) paroxysmal movement disorders. In so doing, the clinical manifestations were lumped into chorea, dystonia and athetosis, either in isolation or combined, using the broader term "dyskinesia". They further divided etiology into primary or secondary (when there was identifiable structural or metabolic abnormality of the central nervous system), or psychogenic disorder. They applied this classification to 46 of their own cases, and further detailed clinical features of the patients including family history, duration and 
phenomenology of the attacks, and comorbidites. Later, hypnogenic paroxysmal dyskinesias were to large extent attributed to epileptiform discharges in genetic forms of frontal lobe epilepsy. $[8,10,11]$

\subsection{Episodic ataxias}

In 1946, while working at the Mayo clinic, Parker observed a series of 11 cases in which patients had abrupt, recurrent attacks of cerebellar dysfunction with nystagmus. Several cases were diagnosed with multiple sclerosis, but he noted that 4 individuals did not have the usual features of typical MS and bore a positive family history, coining the syndrome "periodic ataxia". [12,13] In the ensuing decades, awareness of the condition increased when unrelated kindreds were reported noting autosomal dominant inheritance and a gamut of different symptoms: heterogeneous attacks combining ataxia, dysarthria, nystagmus and vertigo, with variable duration and triggered by alcohol, fatigue and emotional stress; interictal nystagmus, myokymia or carpopedal spasms. [14-20] The serendipitous discovery of acetazolamide [19]responsiveness helped further efforts to classify subtypes of periodic ataxia. Until the 1980s variable terms such as "periodic ataxia" or "paroxysmal ataxia" were used. The header "episodic ataxia" (EA) was later consolidated after a landmark paper by Gancher and Nutt in 1986 describing six kindreds (including one family with 26 members examined) in which the authors distinguished three different syndromes: episodic ataxia with interictal neuromyotonia and positive response to phenytoin (later named episodic ataxia type 1), episodic ataxia with interictal nystagmus which often responded to acetazolamide (later named episodic ataxia type 2) and a third type with combined periodic ataxias and dyskinesias with kinesigenic triggers. [21] In the following decade various linkage analyses studies linked different kindreds and their specific phenotypes to different loci, creating the current nomenclature of EA1, EA2, EA3, etc. In four of these loci genes relating to transmembrane proteins have been identified: KCNA1 for EA1, CACNA1A for EA2, CACNB4 for EA5 and SLC1A3 for EA6.

\section{Classic primary phenotypes and their genetic underpinnings}




\subsection{Paroxysmal kinesigenic dyskinesia}

Primary or idiopathic PKD had diagnostic criteria defined by Bruno and others in a landmark publication 15 years ago, before its genetic underpinnings were unraveled (table 1). [22] These criteria remain useful in the genetic era, although flexibility may be allowed (e.g., age of onset) with recognition of variable expressivity of the underlying genetic causes. It is probably the most common paroxysmal disorder, with an estimated prevalence of 1:250,000 . [23] The prototypical spell is triggered by large amplitude movements of the whole body (or body segment) after a period of rest. Common examples include standing up from a chair, starting to walk/run, turning in bed or jumping into a pool. In some patients startle or the intent to move may also trigger an attack. [24] An attack may be more likely depending on the internal affective state: some patients report that anxiety or stress may lower the threshold for an attack. [22] A premonitory aura is commonly reported, usually an ill-defined sensation of visceral discomfort or focal paresthesia in the affected $\operatorname{limb}(\mathrm{s})$. Some patients may be able to abort an impeding attack when they are experiencing aural symptoms by moving a limb slowly or in a deliberate fashion. [25] The attack commonly includes dystonia with superimposed chorea (dyskinesia), isolated dystonia or chorea is less frequently seen. Attacks are frequently unilateral and asymmetric, but can alternate sides. A small percentage of patients have attacks in bilateral fashion. Anecdotally, dyskinesia with rotation (not lateralization) of the trunk, and patients attempting to immobilize the affected limb with the normal limb are common features. Patients often experience nonkinesigenic attacks[25], often occurring at rest, and rarely exercise-induced episodes[26]. When preceded by a quick movement, usually there is a brief latency of a few seconds before the onset of the attack. Attack duration almost invariably ranges from seconds to less than one minute. Attack frequency is highly variable, ranging from up to 100/day to less than one/week. [27] The disorder appears to be more common in males than females, with a 2-4:1 ratio. $[26,28]$ Imaging and interictal exam are normal in the majority of cases. EEG is usually normal, but focal epileptiform activity has rarely been reported in the intercritical period. $[29,30]$ 
The most common underlying genetic cause underlying PKD is an autosomal dominant mutation in PRRT2, a gene involved in synaptic vesicle exocytosis influencing neurotransmitter release.[31-33] Shortly after this gene was implicated in PKD, it became clear that it was also involved in benign infantile convulsions and the overlap syndrome with PKD, so-called infantile convulsions with choreoathetosis (ICCA syndrome). [34] Later reports have expanded the spectrum of PRRT2-associated disease to febrile seizures, rare cases of episodic ataxia, familial hemiplegic migraine, and one case of benign paroxysmal torticollis of infancy. [27,35-38] Depending on the population ascertained, PRRT2 mutations underlie $21-45 \%$ of sporadic cases; a positive family history increases this number to $77-93 \%$. $[28,39]$ The mean age of onset of PRRT2-associated PKD is close to 10 years, whereas PRRT2-negative is a bit older at 13 years, but confidence intervals overlap. $[27,40]$

Clearly, PRRT2 does not account for all cases of PKD as a condition, and certainly kinesigenic attacks of dyskinesia are not exclusive to PKD and the differential diagnosis is ample. Kinesigenic spells have been associated with various brain abnormalities (see section on secondary paroxysmal dyskinesias) and several neurogenetic conditions, due to mutations in other genes including SLC16A2, KCNA1, ADCY5, SLC2A1, SCN8A, SLC20A2, CLNC1, KCNMA1, DEPDC5 and even PNKD. [40,41] In some of these genetic disorders, PKD may occur as an isolated phenomenon - but may also be complicated by a history of seizures, developmental delay, neuroimaging findings or other paroxysmal motor features. Non-dyskinetic attacks may also be a factor of confusion, with some authors defending an overlap of PKD symptoms with childhood myotonia congenita, caused by mutations in the CLNC1 gene. $[42,43]$ Differentiating features may include cold weather trigger, motor phenomenology restricted to hypertonia in the limb being moved, interictal presence of myotonic discharges on EMG or a family history of myotonia.

\subsection{Paroxysmal non-kinesigenic dyskinesia}


PNKD was the first paroxysmal movement disorder described. [4] Ironically, it remains the most understudied, possibly related to the rarity of the familial forms, and a certain lack of reporting of the more common secondary cases (see section on secondary paroxysmal dyskinesias). Episodic dyskinesia due to phenytoin is an example of a common but underreported condition. In addition, psychogenic movement disorders often manifest as dyskinesia, and it can be difficult to differentiate them from idiopathic PNKD.

PNKD as a condition is clinically diagnosed as spontaneously occurring attacks of involuntary movements, not triggered by sudden voluntary movements or physical exertion. $[9,44]$ In 2004, the gene PNKD (formerly known as MR-1) was associated with the disorder in two kindreds [45] and since then various reports confirmed it to be the main cause of familial PNKD. [44] Patients with PNKD-associated genetic mutations have an earlier age of onset, usually in infancy or early childhood. An older age of onset, usually in early teens, is seen in PNKD-negative cases. [44,46] Alcohol, caffeine, hunger and fatigue are the most common triggers for spells that typically last $10 \mathrm{~min}$ to 1 hour (ranging from few minutes up to 12 hours); attack frequency is highly variable but may occur at least weekly in a large proportion of patients. [44,47] Aural symptoms are seen in 2/3 of cases. [44] The attack semiology is usually comprised of isolated dystonia or choreoathetosis with dystonic contractions, occasionally with oculogyric crises. [46] Attacks may range in severity and one case of fatal laryngeal spasm has been reported. [48]

Suggested criteria for diagnosis PNKD secondary to this gene are listed on table 2. Numerous other genes have been associated with non-kinesigenic episodes of dyskinesia including PRRT2, SLC2A1, KCNMA1, ADCY5, ATP1A3, ATP1A2, PDGFB, FGF14, BCKDC, GLDC, SLC16A2, SCN8A, PDHA1, PDHX, DLAT, ECHS1, SCN1A, and $A L D H 5 A 1 .[26,41,49-52]$ In some of these genes, additional features may be present such as abnormalities on interictal examination, developmental delay, other paroxysmal syndromes, epilepsy, changes on basal ganglia imaging and/or in laboratory investigations for neurometabolic conditions. 


\subsection{Paroxysmal exertional dyskinesia}

After the initial report by Lance, PED was established as a nosological entity when Marsden reported a family with spells of dystonic posturing after exercise. $[5,53]$ The PED phenotype had been known for a while - reported as far back as the $19^{\text {th }}$ century but thought by some to be a harbinger to Parkinson's disease - especially in young adults. [54,55] Marsden noted that the dyskinesia was most likely to occur in the limb that was subject to highest energy expenditure. For example, lower extremity posturing would arise after climbing several flights of stairs, or in the upper extremity after writing for a prolonged period of time. The authors also found that sensory stimulation of the limb, by continuous passive movement or vibration, could also induce a spell - a finding that has not been reported in the literature since.

The prototypical PED spell will involve the lower extremities after a variable period of exercise such as walking or running; usually lasting between 5 and 30 minutes. Nevertheless, patients with predominant involvement of the upper extremities have been reported, such as after prolonged hand use chopping or peeling vegetables. [56]

PED is a heterogeneous entity, and many cases remain idiopathic after genetic investigation. The gene most consistently associated with this phenotype is SLC2A1, which encodes GLUT-1, the major glucose transporter in the brain. [57] PED may also be seen as an early manifestation of dopamine deficiency, specifically with mutations in PARKIN (one of the autosomal recessive genes associated with Parkinson's disease) and GCH1 (associated with dopa-responsive dystonia). [58-60] Several other genes have been implicated, including some involved in energy metabolism ( $P D H A 1, P D H X$, $D L A T, E C H S 1)$ and others in apparently disparate pathophysiological pathways (e.g., CACNA1A, PRRT2, PNKD, ATP1A3, ADCY5 and ALDH5A1). [26,41,61,62]

In patients with SLC2A1 mutations, the phenotype may range from isolated PED to other complex movement disorders, including focal dystonia, ataxia, tremor and 
complex non-kinesigenic paroxysmal movements (including ataxia, chorea and dystonia) that can be severe. [63-69] Additional neurologic features include epilepsy, developmental delay and migraine. In milder cases the interictal examination and imaging may be normal, and EEG may be informative. On one hand, seizures are associated with mutations in SLC2A1. On the other, cases have been described of exertion-induced seizures in patients with pre-existing epilepsy (mostly in the pregenetic era). [70] Therefore, genetic or non-genetic forms of epilepsy are an important differential diagnosis of spells even if they appear to be triggered by exercise.

\subsection{Paroxysmal hypnogenic dyskinesia}

The clinical syndrome of PHD was first described in 1981, with dyskinetic movements arising out of NREM sleep and negative recording on surface scalp EEG in the ictal and interictal periods. [8] In many described cases, the duration was short (usually $<2 \mathrm{~min}$ ), but the frequency was variable and in general would respond to carbamazepine. [10,11] Further studies demonstrated that these were epileptic seizures arising from the mesioorbital region, with epileptiform activity detected with invasive zygomatic and sphenoidal leads. The syndrome was then re-named nocturnal frontal lobe epilepsy (NFLE). Some familial cases have been associated with mutations in genes encoding for subunits of the acetylcholine receptor leading to a gain of function (CHRNB2, CHRNA2, CHRNA4). [71] Other genes implicated in familial cases include KCNT1 and DEPCD5. [72,73] The recognition of extrafrontal epileptic activity in some cases has led some authors to abandon NFLE and suggest the term "sleep hypermotor epileptic activity". [74]

Nevertheless, rare cases highly suggestive of movement disorder without epileptic origin had been previously described in pre-genomic era. [75] Recently, PHD has made a comeback as a non-epileptic event, with recognition that some patients with mutations in PRRT2 and $A D C Y 5$ can manifest at least initially as predominantly nocturnal dyskinetic events, although more often the manifestations are not exclusively nocturnal.[76-78] $A D C Y 5$, initially defined as relatively "benign" disorder causing mainly 
mild chorea and facial dyskinesias, is now known to involve complex phenotypes and often neurodevelopmental aspects.[79]

Practically speaking, it may be difficult to distinguish epileptic hypnogenic dyskinesias from epileptic events, since both dystonic posturing and hypermotor behavior have been described in both. The phenomenology of NFLE is pleomorphic including movements that phenomenologically could be described as dystonic and/or dyskinetic.[80] Video EEG may provide phenomenological evidence, but the sensitivity of the test is very low for patients with infrequent attacks and also for those with deep frontal foci. The scalp surface EEG is often normal in NFLE. Monitoring with intracerebral leads may be considered but is an invasive diagnostic modality. Polysomnography may help determining that events occur out of NREM sleep, are usually stereotyped and may be temporally preceded by $\mathrm{K}$ complexes, separating the disorders from some parasomnias.[80] As discussed in the diagnosis section, genetic testing may be paramount in these cases.

\subsection{Episodic ataxia type 1}

In 1994, the then-called entity "episodic ataxia with myokymia" was found to be associated with point mutations in the gene KCNA1, coding for the voltage-gated potassium channel $\mathrm{K}_{\mathrm{v}}$ 1.1. [81] It was re-labeled Episodic Ataxia type 1 (EA1), distinguishing it from "acetazolamide-responsive episodic ataxia" (thereafter labeled Episodic Ataxia type 2 - EA2). It was the first channelopathy described to affect the human brain. The initial report of the syndrome is attributed to Van Dyke, who beautifully described a family with spells of episodic unsteadiness and shaking, diplopia and dysarthria that could be triggered by sudden movement, with increased susceptibility in the setting of fatigue, hunger or emotional upset. [17] Interictally, individuals had undulatory, rippling movements in large (e.g., hamstrings and gastrocnemii) and small muscles (e.g., giving rise to piano-playing motion of the fingers), labeled as myokymia. Some individuals had seizures. Finally, he noted that some patients would have a fixed hand posture resembling carpopedal spasm, a finding 
that has been replicated in genetically confirmed subjects and may be of diagnostic value. [41]

The episodes of EA1 tend to have onset in early childhood, with mean age of onset 7.8 years. [82] Attacks are most commonly triggered by exertion, emotional/physical stress and changes in environmental temperature. Dietary factors (e.g., caffeine, alcohol, others), sudden movement and startle may also precipitate an attack. Aural symptoms, such as a feeling of imbalance, falling or weakness, precede the spells. [83] Most often, attacks are short lived ( $<15$ minutes), with variable frequency that tends to decrease with age. $[82,84]$ Longer attack duration has anecdotally been described, but appears to be rare. [85] The clinical characteristics are highly variable, and contrary to the paroxysmal dyskinesias they are not stereotyped, with great intraindividual variability. The core features include imbalance, incoordination and slurred speech. [82] Tremors/twitching, when present, likely represents an exacerbation of underlying myokymia. Some patients will report associated weakness, muscle stiffening, and visual disturbance. Breathing abnormalities ("paroxysmal dyspnea") have been described. [86] Vertigo may or may not be present. [84]

During and between attacks, patients with EA1 can have myokymia, manifesting clinically as intermittent cramps, stiffness, twitching, or undulating/rippling activity in muscles. More sustained abnormal muscle contractions may also occur and are referred to as neuromyotonia. [86] This is possibly the underlying cause of the distal muscle contraction resembling carpopedal referred to above and an important differential diagnosis with dystonia. In between attacks, myokymia may be clinically visible or only detectable with EMG recording. [83] Myokymia is neither specific (patients with EA3 can also have them) nor sensitive - EA1 patients without myokymia have been described. [85] Conversely, neuromyotonia and/or myokymia without ataxia can be seen. $[83,87]$ Other neuromuscular features may include painful stiffness, distal weakness, moderate muscle hypertrophy and increase in muscle tone with hypercontracted posture. $[87,88]$ Additional clinical features include seizures, hearing impairment, postural tremor and shortening of the Achilles tendon, occasionally 
requiring corrective surgery. Hypomagnesemia has been described in a few cases. $[89,90]$ Interictal EEG may show non-specific slowing or epileptiform activity in some cases. Neuroimaging is usually normal. [91] About $20 \%$ of patients will accumulate progressive cerebellar ataxia, affecting activities of daily living and deteriorating quality of life - but rarely rendering the individuals completely disabled.[82]

\subsection{Episodic ataxia type 2}

Shortly after the discovery of the genetic underpinning of EA1, EA2 was found to be allelic with familial hemiplegic migraine type 1 (FHM1) and associated with point mutations with CACNA1A, the gene coding for the voltage-sensitive $\mathrm{Ca}_{\mathrm{v}} 2.1$ subunit of the $P / Q$ calcium channel. [92-95] In the pre-genetic era, EA2 had been previously referred to as "paroxysmal ataxia with acetazolamide responsiveness" or "episodic ataxia with interictal nystagmus". [19,21] Molecular biology studies further added support to the pathophysiological role of altered calcium channels in disease by finding high levels of expression in cerebellar Purkinje and granular cells and their role in neurotransmitter release. [96,97] A subgroup of patients with late-onset, progressive ataxia was found to have polyglutamine expansions in the CACNA1A gene. [98] When such mutation is present, the disease is referred to as Spinocerebellar Ataxia type 6 (SCA6) .

Similar to PRRT2, CACNA1A is a gene with several allelic disorders. Besides FHM1 and EA2, patients may have progressive, chronic ataxia (independent of polyglutamine expansion), fluctuating weakness, epileptic seizures, interictal dystonia and paroxysmal dyskinesia. [99-102] In fact, neuromuscular transmission may be altered in patients harboring CACNA1A mutations, with increased jitter and blocking on single fiber EMG.[100] 
EA2 is probably the most common episodic ataxia, with a prevalence estimated at 1:100,000. [84] Clinically, EA2 has onset in the first two decades of life. Patients usually have recurrent spells of imbalance, vertigo and nausea that are longer lasting ( $>10$ minutes), potentially extending to several hours or even days. [84,91] Besides ataxia, patients may also have nystagmus, diplopia, dysarthria, weakness and dystonia. [84] The frequency is quite variable, and common triggers include exercise, emotional or physiological stress (fever, high environmental temperature) and dietary factors (alcohol, caffeine). [91,103] Interestingly, phenytoin may trigger attacks in some subjects. [91] Up to $50 \%$ of patients will have migraines. [104]

Most patients with EA2 will have interictal nystagmus, gaze-evoked or primary position downbeating. [91] Other features of cerebellar dysfunction can be seen, such as ocular dysmetria, slowing of mean saccade velocity and gradual progressive ataxia in up to $50 \%$ of EA2 patients. [105] Uncommon clinical features of CACNA1A mutations include developmental delay, abdominal pain, strabismus, hyperactivity, paroxysmal torticollis of infancy, blepharospasm and other focal dystonias. [106-110] Similar to EA1, EEG may demonstrate interictal slowing or epileptiform activity. Neuroimaging is informative, as MRI often shows midline cerebellar atrophy - especially in patients with longstanding symptoms.[91]

\subsection{Other episodic ataxias}

There are in total 8 episodic ataxias subtypes described so far, as well as a few other genes implicated with the EA phenotype but with other neurological features. Besides EA1 and EA2, EA6 has been the best characterized. [111] Mostly, other cases of EAs have been described in one or two families. Genetic loci have been mapped to EA 3, 7 and 8; EA5 has been mapped but it is a bit controversial [111]The clinical phenotypes of these main subtypes are listed on table 3.

EA3 has autosomal dominant inheritance and linkage to a region on chromosome 1p42, identified on a Canadian Mennonite family. [14,112,113] Episodes are short-lasting, 
distinctly associated with tinnitus, and no interictal myokymia. EA4, previously named periodic vestibulocerebellar ataxia, was suggested at the time of the designation of EA3. [113] It appears to be phenotypically similar, but with age of onset between the $3^{\text {rd }}$ and $6^{\text {th }}$ decade and presence of oculomotor abnormalities. [14,114]

EA 5 has been associated with mutations in CACNB4 (encoding a subunit of a calcium channel), has variable expressivity with different kindreds manifesting with idiopathic generalized epilepsy, juvenile myoclonic epilepsy and episodic ataxia. The designation of this gene as the culprit has been questioned given the presence of the variant allele in the normal population and individuals with the same variants with distinct phenotypes (e.g., epilepsy without ataxia). [111] Spells in EA5 are phenotypically similar to EA2, but the age of onset may be in adulthood. [115]

EA6 has been associated with mutations in the sodium-dependent glutamate/aspartate transporter EAAT1, encoded by the SLC1A3 gene. [116] The phenotype is similar to EA2, and may affect up to $5 \%$ of patients with a suggestive clinical presentation who are negative for CACNA1A - but, once again, the age of onset can be as late as the $6^{\text {th }}$ decade. [117] Additional phenotypic features include hemiplegic migraine, seizures and mild cognitive impairment. [118]. Other neuropsychiatric conditions have been associated with changes in SLC1A3, such as Tourette syndrome (missense mutation), ADHD and autism (duplications).[119,120] EA7 has been linked to chromosome 19q13, and is phenotypically similar to EA2, but there are no interictal findings. [121]

EA8 was mapped a region spanning chromosome 1p36.13-p34.3. The area includes 2 genes, HSPG2 and UBR4, but the author favored the latter as the culprit given its biochemical interactors. [122] Similar to EA1, onset was described in early infancy, but spells last longer (several hours). Although present, interictal oculomotor abnormalities are not as pronounced as in EA2.

\section{Secondary paroxysmal movement disorders}


Various conditions can manifest as paroxysmal dyskinesias. In a retrospective review, up to $22 \%$ of all recurrent paroxysmal movement disorders (excluding episodic ataxias) were attributable to a structural central or peripheral nervous system lesion[123] The movements are usually manifest as isolated dystonia or with concurrent hyperkinetic movements such as chorea; they may be occasionally painful. Secondary cases are more likely to have an abnormal interictal neurological or clinical examination, demonstrate variability in duration and frequency and present with overlapping triggers (e.g., PKD and PNKD on a same patient). [123] Many cases have a later age of onset, although establishing causation is not straightforward: there can be a long delay between injury and motor manifestation. Useful clinical features to different primary and secondary paroxysmal dyskinesias are listed on table 4. None of these features is definitive for secondary paroxysmal dyskinesias. Therefore, when working up patients clinicians should use their judgement to determine the appropriateness of additional investigations ( e.g., neuroimaging or metabolic studies) based on the presence of atypical features, absent family history or abnormalities on the interictal clinical examination

Many causes of secondary paroxysmal dyskinesias have been reported, and studies evaluating the most frequent etiologies may be subject to referral bias. In the literature, demyelinating lesions, cerebrovascular disease, trauma and metabolic disorders seem to be most commonly reported. Various drugs targeting the central nervous system can cause chorea or ataxia, and in some of those the disturbance can be intermittent. Episodic ataxia or chorea related to use of anti-epileptic drug is not an uncommon finding in clinical practice, but are conversely rarely reported in the literature. Table 5 lists several causes of secondary paroxysmal dyskinesias. .

A sizeable proportion of paroxysmal dyskinesias may be functional in origin (also named "psychogenic", despite the fact that a direct link to psychopathology is not always found). It is important to be cautious when diagnosing a disorder with intermittent symptoms as functional: clinicians should not use the episodic nature as an exclusive clue to a functional disorder. This "false red flag" has lead many patients with 
genetically proven paroxysmal movement disorders to be diagnosed with or suspected of having a functional condition. In a seminal retrospective cohort of 92 patients from Blakeley and Jankovic, 21 patients had a functional paroxysmal dyskinesia diagnosis based on the presence of false sensory examinations, psychiatric disorders, inconsistent neurological findings and other criteria for functional movement disorders.[123] Table 6 lists some semiological clues for the diagnosis of functional paroxysmal dyskinesias. The functional paroxysmal dyskinesia category may be particularly enriched for the non-kinesigenic subtype. In the previously cited paper published by Demirkiran and Jankovic, functional cases accounted for 35\% of the PNKD cohort. [9]

Lastly, episodic ataxias or paroxysmal dyskinesia may be seen as part of the phenomenology in complex syndromes associated with mutations in other genes. Neurometabolic disorders often manifest with episodic phenomena, or episodic worsening of pre-existing symptoms. Various mitochondrial disorders have been consistently associated with paroxysmal dyskinesia (mainly exercise induced) and episodic ataxia.

\section{Diagnosing paroxysmal movement disorders}

\subsection{Determine the phenotype}

The phenomenology of the movement disorder helps the clinician classify the attacks and often the whole disorder into diagnostic categories. Since interictal examination is often normal, the use of home videos can be invaluable to appropriately determine if dystonia, chorea, ataxia or some combination is the best descriptor for the event. Detailed history and clinical maneuvers to trigger spells in clinic can also be important: asking the patient to suddenly and quickly stand up from a chair, run, perform exercises, and so forth may bring on kinesigenic or exertional attacks. The presence of pain should be a red flag - dystonia is usually not painful, whereas neuromyotonia related to mutations in KCNA1 can present as an uncomfortable cramp. [41] Patients should be 
inquired about the presence of sensory aura, which may be only elicited by direct questioning. In PKD patients that do not have an aura (and if the events are restricted to only the limb that is moved), it may be helpful to test for grip or percussion myotonia, and inquire about a family history. Some patients with myotonia congenita may resemble PKD. [42]

Subsequently, identification of the most consistent triggers is important. A repeat clinic visit, after an initial explanation and patient-recorded log of events may help clarify. Kinesigenic triggers are obviously relevant to PRRT2-associated dyskinesias, but can also be seen in other paroxysmal dyskinesia genes and episodic ataxia type 1. Kinesigenic triggers should allow one to include the possibility of PRRT2, KCNA1 and other disorders described above. In other words, it may anchor the diagnostic thought process as patients with kinesigenic triggers may also have concomitant nonkinesigenic or exertional triggers.

Dietary and environmental triggers can also be informative. In PNKD, fatigue, alcohol, smoking and caffeine can precipitate an attack. The same is true in some of the episodic ataxias, with ambient temperature also listed as influencing the likelihood of an attack to happen (see table 3). Emotional stress can also be a trigger (or at least lower the threshold for an episode to occur) in several of the paroxysmal dyskinesias and episodic ataxias. The presence of an emotional trigger does not necessarily equate to a functional etiology to the attacks. As previously discussed, consistency may be more informative. Later age of onset, incongruency between triggers and spells and variability may be more sensitive indicators to a functional etiology (table 6 ).

Exertional triggers are a clue to $S L C 2 A 1$ mutations, but have also been described in dopamine depleted states (e.g., early onset Parkinson's disease or neurotransmitter synthetic defects) as well as mitochondrial disorders, among others. The movement phenomenology in SLC2A1 mutations is quite rich, and combinations of dystonia, chorea and ataxia can be seen. Patients with SLC2A1-related epilepsy will often fail to report PED attacks, or see them as epileptic equivalents, so patient education is 
paramount. Episodic ataxias can also be triggered by exercise, but appear to be more related to the excitement, heat or exhaustion produced by the activity. Contrary to the EAs, the exertional trigger in PED is most likely to cause motor phenomena in the limb that is subject to the highest energy expenditure.

\subsection{Initial investigation}

The diagnosis of some paroxysmal disorders can exceptionally be made on clinical grounds alone. In cases with a positive family history, especially if one member has been genetically confirmed, assuming a genetic diagnosis is appropriate, although phenocopies have been reported in several neurogenetic conditions. Ruling out structural or metabolic causes of paroxysmal event is a rule, and brain imaging either through CT or MRI is warranted for most cases. Thorough history of drug use including prescription and non-prescription drugs should always be performed. Blood sugar, electrolytes (including calcium, magnesium and phosphate), liver, kidney function and thyroid hormones can help diagnose a large part of secondary secondary paroxysmal movement disorders. EEG may determine the nature of the events or demonstrate coexisting epileptic discharges that may be informative of the underlying genetic cause. Several "paroxysmal" genes can have co-morbid epilepsy, such as PRRT2, CACNA1, $S L C 2 A 1, K C N A 1$ to name a few. As discussed previously video EEG may provide phenomenological evidence, but the sensitivity of the test is very low for patients with infrequent attacks and it may be falsely negative for those with deep foci.

Even without genetic confirmation or family history, classic cases of primary PKD can be successfully managed with a low dose anti-epileptic trial.

Some authors have proposed additional investigations depending on the phenotype. For example, in paroxysmal exertional dyskinesia a lumbar puncture can be helpful to determine CSF glucose, lactate, biogenic amines and pterin levels.[124] The procedure should be done after 4-6 hours of fasting and blood should be obtained prior to the LP to avoid stress-induced hyperglycemia. Findings suggestive of GLUT1 deficiency 
syndrome include a low CSF glucose ( $\leq 10$ th percentile), CSF to blood glucose ratio $\leq 25$ th percentile and CSF lactate $<90^{\text {th }}$ percentile. Age-normative data has been published. [125] Low CSF HVA and 5-HIAA, coupled with low tetrahydrobiopterin levels are suggestive of a dopaminergic synthetic defect such as $\mathrm{GCH} 1$ deficiency. In older patients with a PED phenotype, a dopamine transporter scan may be informative as suggested by Erro et al. [124] If abnormal, it suggests the presence of an underlying parkinsonian disorder, such as idiopathic Parkinson's disease or young-onset parkinsonism, which often has an underlying genetic etiology.

\subsection{Genetic investigation}

Prior to ordering genetic tests, one should have a suspicion of the most likely genetic culprits and knowledge whether the suspected underlying variant occurs at the chromosomal, DNA, exon, gene or nucleotide level. This allows for selection and critical interpretation of genetic testing. Clinicians need to be mindful of the shortcomings specific to the different types of genetic tests available. Large gains, losses or rearrangements in DNA (>5Mb) can be evaluated by karyotype. Smaller copy number variants can be picked using microarray technology. [126] For example, in a patient with dysmorphisms, developmental delay and PKD phenotype, a chromosomal microarray is more likely to detect a microdeletion encompassing 16p11.2 (that includes the PRRT2 gene) than single gene sequencing. [25] When the gain or deletion is at the gene or exon level (such as $13 \%$ of patients with Glut 1 deficiency syndrome), other techniques will be necessary such as multiplex-ligand probe assay (MLPA). [127]

Lastly, if the genetic variant is at the nucleotide level, traditional (Sanger) or next generation sequencing (NGS) can be used. The use NGS with phenotype-specific gene panels has become widespread in neurological practice when such resources are available. With the increase in genes associated with the paroxysmal disorder phenotype, it has however become increasingly hard to have truly comprehensive panels that include all genes have associated with a particular phenotype. Nevertheless, if a select group of genes is highly suspected, panels may provide higher 
coverage and sensitivity than methods that screen all coding regions of DNA, such as whole exome sequencing. Improved process in variant filtering, calling and bioinformatic analysis are likely to expand the use of whole exome sequencing in clinical practice.

The clinician may also recall that sequencing techniques such as NGS are unlikely to pick up on repeat expansion disorders, a caveat that may relevant if the phenotype is episodic ataxia. Poly-CAG repeats have been described in CACNA1A (although most commonly the repeat expansion would cause a progressive ataxic syndrome). [128] Such genetic variant would require Southern Blot analysis to be detected. [129]

\section{Treating paroxysmal movement disorders}

\subsection{Empiric therapy}

Treatment of the paroxysmal dyskinesias has largely been empirical. Most of the medicines currently used have emerged as effective with the presumption the underlying pathophysiology represented ion channel dysfunction or a form of epilepsy, even if later these hypotheses were disproven. To this day, a more precise mechanistic understanding of the pathophysiology of these conditions is still in its infancy, with the discovery that several disorders share different levels of dysfunction at the membrane or synaptic level. $[33,130]$

The use of antiepileptics (originally phenytoin) was first reported as unsuccessful in the original description of paroxysmal nonkinesigenic dyskinesias by Mount and Reback, and later reported be effective in the kinesigenic form by Kertesz, leading early support to the theory that these episodes could be epileptic. [4,131] Nevertheless, as early as in the 1970 s this theory was disputed with some patients with the PKD phenotype responding to levodopa administration. [132] Pathophysiological considerations aside, PKD remains very sensitive to antiepileptic drug therapy, with multiple agents reported efficacious, in particular those that modulate activity of the sodium channels. Arguably, the use of low dose $(10 \mathrm{mg} / \mathrm{kg} /$ day) carbamazepine as first line therapy is more a by- 
product of time-honored empirical evidence than comparative effectiveness to other agents.

The episodic ataxias have threaded a similar serendipitous journey. Early investigators found that then available antiepileptic agents (including phenytoin and benzodiazepines) were ineffective, but acetazolamide - initially purported as an effective antiepileptic agent - was found to be successful in preventing some attacks. [19,133] At the time of its first usage, the drug was prescribed based on the wrongful assumption that the pathophysiology of EA was similar to hypokalemic periodic paralysis, for which the drug had proven efficacy. [19,134]

The rarity of these conditions has further precluded head-to-head trials to determine the most efficacious drugs. To this day, only one agent (4-aminopyridine, for the treatment of episodic ataxia type 2) has been rigorously studied in evidence-based fashion by modern standards. [135]

\subsection{Phenotype oriented therapy}

Phenotypically characterizing patients is invaluable and greatly assists in the initial treatment strategy. For example, patients with primary or secondary PKD may respond to carbamazepine. In such situation, the results of genetic testing may not necessarily influence the treatment decision since a trial of this agent may be effective even if results are negative or equivocal. [40] Furthermore, in some situations genetic testing may be unavailable (due to local resources, insurance coverage or others) or have delayed results.

Patients with the PNKD phenotype, especially if they fulfill Bruno's criteria (table 2) have a higher likelihood of being associated with mutations in the PNKD gene and therefore respond to benzodiazepine treatment.[44] Even if mutations in PNKD are absent patients may have a transient response to clonazepam or diazepam, although it may be less sustained. 
Also, the specific genotype may not be necessary to treat some patients if the combination of clinical features and laboratory abnormalities suggest a particular diagnosis. For example, in a patient with complex motor phenotype that includes PED with low CSF glucose and lactate, arguably institution of dietary measures to treat presumptive GLUT1 deficiency could provide benefit prior to diagnostic confirmation by gene testing. Gene testing may not be determinant and SLC2A1-related PED can respond to levodopa. [136]Clinical judgement may determine if a trial of other agents triheptanoin or acetazolamide - should be considered. In patients with clinical features suggestive of a dopa-responsive dystonia with superimposed paroxysmal events, a levodopa trial should be entertained. [58] Finally, patients with an EA phenotype may benefit from an acetazolamide trial regardless of genotype. In one of the rare documented cases of PRRT2-realted episodic ataxia, the patient responded well to acetazolamide. [137]

\subsection{Genotype oriented therapy}

Genetic confirmation of the diagnosis is ideal whenever possible and can provide precision treatment in some conditions. For example, in patients with confirmed mutations in PRRT2, the literature supports the use of carbamazepine as first line therapy for paroxysmal dyskinesia or hemiplegic migraine. Clinicians may also consider determining the specific HLA haplotype in their patients: such screening practice appears to be cost-effective in determining the risk of carbamazepine-associated Steven Johnson Syndrome/Toxic Epidermal Necrolysis, particularly in the Asian population.[138-140] Other antiepileptic drugs may be useful, particularly those with sodium channel blocking activity.

In patients with the PNKD and PED phenotype, genetic testing results may inform treatment especially if one of the less common genetic causes is found. For example, levodopa can be considered if there is a mutation in one of the genes implicated in the biogenic amine synthetic pathway or in one of the early-Parkinson's disease genes - 
regardless of the kinesigenic or non-kinesigenic nature of the attacks. Specific measures need to be taken regarding diet and supplementation if one of the mutations associated with energy metabolism is found, and given that mitochondrial disorders can cause either paroxysmal dyskinesia or episodic ataxia, the first target of the therapy should be initially the metabolic abnormality. Similarly, in episodic ataxias there may be specific treatment instituted such as 4-aminopyridine for mutations in CACNA1A or flunarizine for ATP1A3. More invasive treatments, such as deep brain stimulation, are not routine but in refractory cases knowing the underlying genetic mutation may bolster the decision to pursue a surgical therapy with higher likelihood of successful outcome. DBS has been successfully employed in a few cases of GNAO1, ADCY5 and PNKD.

\section{Conclusion}

Due to recent advances in neurogenetics, the diagnosis of paroxysmal movement disorders has progressed significantly and can help target initial or rescue therapy in the various presentations of paroxysmal dyskinesia and episodic ataxia. 


\section{Expert Opinion}

We provide advice on the treatment of the main forms of paroxysmal movement disorders, whenever possible informed by phenotype and genotype. Given the paucity of evidence, treatments should be discussed with patients and families taking into account preferences, risk-benefit and local specificities.

$P K D$

Treatment of PKD is largely based on the clinical diagnosis. Patients often improve with low dose of anticonvulsants medicines. Carbamazepine is the most studied drug, with over $90 \%$ improvement - especially if $P R R T 2$-associated. $[27,28,40]$ Other anticonvulsants reported useful include phenytoin, oxcarbazepine and lamotrigine [141]. Attacks may undergo complete or partial remission after age 20 , more commonly in PRRT2-positive cases. [27,28,40]

\section{$P N K D$}

Benzodiazepines seem to be helpful in PNKD. In patients with PNKD gene mutations, clonazepam or diazepam improved attacks in up to $50 \%$ of patients. $[44,142]$ The benefit in gene-negative cases or other genes is less well studied, with some patients having initial good response that is not sustained. [44] Other drugs may have variable benefit, such as levetiracetam or acetazolamide. $[48,143]$ Deep brain stimulation has been anecdotally successful in refractory severe cases. [144]

PED 
In patients with SLC2A1 mutations, the ketogenic diet (or the more palatable modified Atkins diet) can be helpful in alleviating the movement disorder. [145] Triheptanoin appears useful in decreasing the frequency of attacks. [146,147] Other medications with variable success include acetazolamide, levodopa, gabapentin and carbamazepine. [136,148-150]

PHD

Empirical treatment with an antiepileptic agent may be reasonable. Given the overlap with several epilepsy syndromes, treatment recommendations fall outside the scope of this review.

Episodic Ataxia type 1

Carbamazepine at modest doses will anecdotally improve attacks in most individuals, but this has not been replicated in a prospective study. [82] Other medicines with variable success include valproic acid and acetazolamide. $[87,88]$

\section{Episodic Ataxia type 2}

Acetazolamide can alleviate attack frequency in up to $2 / 3$ of patients with EA2, although it does not affect underlying ataxia progression. [105] An international, double-blind, placebo-controlled trial demonstrated that 4-aminopyridine improves attack frequency and quality of life. [135] Segmental dystonia in a patient with CACNA1A has been successfully treated with DBS to the globus pallidus. [110]

\section{Other conditions}

The treatment of other genetic forms of paroxysmal dyskinesia or episodic ataxia should be directed mainly at the current clinical practice regarding these specific conditions. Neurometabolic disorders should be appropriately managed. Neurotransmitter synthesis 
defects should be cautiously treated in the context of specific enzymatic defects and the likelihood of benefit of dopaminergic medicines. EA 5 and EA6 may improve with acetazolamide; EA8 may be sensitive to clonazepam.

Secondary PKD cases may respond well to carbamazepine or other anticonvulsants. [123] Patients with secondary mixed PKD/PNKD may respond to clonazepam; PNKD has responded to trihexyphenidyl or tetrabenazine. In patients with demyelinating lesions with tonic spasms, acetazolamide can be helpful. [151]

Functional paroxysmal dyskinesias benefit largely from appropriate diagnosis and multidisciplinary approach. Proper explanation and discussion of the diagnosis with the patient is of paramount importance. Specialized physical therapy and cognitive-behavior therapy may be considered. 


\section{Five-year view}

Given the rapid advance in neurogenetics and the sustained interest in paroxysmal movement disorders it is likely that in the following years we might see a clarification of the familial cases which are negative for testing for known mutations, and a continued growth of the known phenotypic spectrum of manifestations of known and new genes. Episodic abnormalities of movement are a common finding in various conditions and hopefully the enhanced interest will lead to a better characterization of these phenomena in daily neurological practice as well as management strategies. 
Table 1: Criteria for Paroxysmal Kinesigenic Dyskinesia (from ref [22])

\begin{tabular}{|l|}
\hline Age at onset between $1-20$ years \\
\hline Identified kinesigenic trigger for the attack \\
\hline Short duration of the attack $(<1$ minute) \\
\hline Control of attacks with phenytoin or carbamazepine \\
\hline
\end{tabular}

Table 2 - Criteria proposed for PNKD (adapted from ref [44])

Hyperkinetic, involuntary dyskinetic spells usually lasting 10min-1 hour (up to 4 hours)

Normal interictal examination

Onset in infancy or early childhood

Secondary causes excluded

Attacks precipitated by caffeine and/or alcohol

Family history of movement disorder with above features

Table 3- Phenotypes of main episodic ataxias subtypes (adapted from $[111,115,117,118,121,122,152])$

\begin{tabular}{|c|c|c|c|c|c|c|c|c|}
\hline & EA1 & EA2 & EA3 & EA4 & EA5 & EA6 & EA7 & EA8 \\
\hline Gene/loci & $\begin{array}{l}\text { KCNA1 } \\
(12 \mathrm{p} 13)\end{array}$ & $\begin{array}{c}\text { CACNA1A } \\
(19 \mathrm{p} 13)\end{array}$ & $1 q 42$ & $\mathrm{~N} / \mathrm{A}$ & $\begin{array}{c}\text { CACNB4 } \\
(2 q 22-23)\end{array}$ & $\begin{array}{l}\text { SLC1A3 } \\
\text { (5p13.2) }\end{array}$ & $\mathrm{N} / \mathrm{A}$ & $\begin{array}{c}\text { ? UBR4 } \\
\text { (1p36.13) }\end{array}$ \\
\hline $\begin{array}{l}\text { Age of } \\
\text { onset }\end{array}$ & $<20$ & $<20$ & $1-40 s$ & $20-50 s$ & $20-60$ & Infancy-50s & $<20$ & Infancy \\
\hline Duration & Sec-Min & $\begin{array}{l}\text { Hours- } \\
\text { Days }\end{array}$ & Min-Hours & "brief" & Hours & Hours-days & Hours-days & $\begin{array}{l}\text { Min to } \\
\text { hours }\end{array}$ \\
\hline Triggers & $\begin{array}{l}\text { kinesigenic, } \\
\text { stress, fever, } \\
\text { heat, diet } \\
\text { (caffeine, } \\
\text { alcohol), } \\
\text { startle, fatigue }\end{array}$ & $\begin{array}{l}\text { Exertion, } \\
\text { fatigue, } \\
\text { stress, } \\
\text { excitement }\end{array}$ & $\begin{array}{l}\text { Stress, fatigue, } \\
\text { sudden changes } \\
\text { in head position, } \\
\text { arousal from } \\
\text { sleep }\end{array}$ & $\begin{array}{l}\text { Changes in } \\
\text { head position, } \\
\text { fatigue, } \\
\text { environmental } \\
\text { motion }\end{array}$ & $n / a$ & $\begin{array}{l}\text { Fever, stress, } \\
\text { heat, smoking }\end{array}$ & $\begin{array}{l}\text { Excitement, } \\
\text { exercise }\end{array}$ & $\begin{array}{c}\text { Anxiety, } \\
\text { cold, stress }\end{array}$ \\
\hline $\begin{array}{l}\text { Attack } \\
\text { features } \\
\text { (besides } \\
\text { ataxia) }\end{array}$ & $\begin{array}{l}\text { dysarthria, } \\
\text { weakness, } \\
\text { tremor, } \\
\text { muscle spasm }\end{array}$ & $\begin{array}{c}\text { Vertigo, } \\
\text { diplopia, } \\
\text { weakness, } \\
\text { headache, } \\
\text { tonic } \\
\text { upgaze, } \\
\text { dystonia }\end{array}$ & $\begin{array}{l}\text { Vertigo, diplopia, } \\
\text { weakness, } \\
\text { tinnitus, } \\
\text { headache, visual } \\
\text { blurring }\end{array}$ & $\begin{array}{l}\text { Vertigo, } \\
\text { diplopia }\end{array}$ & Dysarthria & $\begin{array}{l}\text { Weakness, } \\
\text { seizure }\end{array}$ & $\begin{array}{l}\text { Dysarthria, } \\
\text { weakness }\end{array}$ & $\begin{array}{l}\text { Dysarthria, } \\
\text { weakness }\end{array}$ \\
\hline $\begin{array}{l}\text { Interictal } \\
\text { features }\end{array}$ & Myokymia & $\begin{array}{l}\text { Nystagmus } \\
\text { Ataxia }\end{array}$ & Myokymia & $\begin{array}{l}\text { Nystagmus, } \\
\text { abnormal } \\
\text { smooth } \\
\text { pursuit }\end{array}$ & $\begin{array}{l}\text { Nystagmus, } \\
\text { ataxia }\end{array}$ & $\begin{array}{l}\text { Nystagmus, } \\
\text { ataxia }\end{array}$ & None & $\begin{array}{c}\text { Nystagmus, } \\
\text { ataxia, } \\
\text { myokymia, } \\
\text { tremor }\end{array}$ \\
\hline $\begin{array}{l}\text { Additional } \\
\text { features }\end{array}$ & Seizures & $\begin{array}{c}\text { Seizures } \\
\text { Hemiplegic } \\
\text { migraine, } \\
\text { BPTI, PTU }\end{array}$ & Seizures & Seizures & & $\begin{array}{l}\text { Cognitive } \\
\text { impairment, } \\
\text { Hemiplegic } \\
\text { migraine }\end{array}$ & & $\begin{array}{l}\text { "warning } \\
\text { feeling" } \\
\text { prior to } \\
\text { attack in } \\
\text { one patient }\end{array}$ \\
\hline
\end{tabular}

${ }^{*}$ Additional features may or may not be present in a given patient. BPTI = benign paroxysmal torticollis of infancy, PTU = paroxysmal tonic upgaze. Please note other genes have been associated with episodic ataxia - refer to main body of text. 
Table 4 Primary vs Secondary Dyskinesias

\begin{tabular}{|l|l|}
\hline Primary & Secondary \\
\hline Early age of onset & Onset in adulthood \\
\hline Normal interictal examination & $\begin{array}{l}\text { Baseline findings on exam (depending on } \\
\text { cause) }\end{array}$ \\
\hline Positive family history & No family history \\
\hline Reasonably constant clinical features & Variability in duration and frequency \\
\hline Reasonably constant trigger & May have mixed triggers \\
\hline
\end{tabular}

Table 5 Examples of Secondary Dyskinesias (adapted from refs [123,153])

\begin{tabular}{|l|l|l|}
\hline Cause & Phenomenology & Clinical clues* \\
\hline Demyelinating disease & $\begin{array}{l}\text { PKD, PNKD, EA, } \\
\text { "tonic spasms" }\end{array}$ & $\begin{array}{l}\text { Abnormal brain or spine MRI; OCBs in the } \\
\text { CSF }\end{array}$ \\
\hline $\begin{array}{l}\text { Cerebrovascular disease } \\
\text { (e.g., TIA, Stroke, Moya } \\
\text { Moya) }\end{array}$ & PKD, PNKD, EA & $\begin{array}{l}\text { Contralateral to disease area, most often } \\
\text { BG, subcortical WM or brainstem, } \\
\text { headaches or seizures (Moya Moya), } \\
\text { abnormal vessel imaging }\end{array}$ \\
\hline CNS trauma & PKD, PNKD & Other neurological deficits from trauma \\
\hline PNS Trauma & PKD, PNKD & $\begin{array}{l}\text { Controversial; may have previous hx of } \\
\text { neurological disease; most often delayed } \\
\text { presentation of dystonic posturing in the } \\
\text { myotomal distribution, paresthesias }\end{array}$ \\
\hline $\begin{array}{l}\text { Hypoxic-ischemic injury } \\
\text { Kernicterus }\end{array}$ & PKD, PNKD & $\begin{array}{l}\text { May have delay between injury and } \\
\text { presentation }\end{array}$ \\
\hline $\begin{array}{l}\text { Infections (syphilis, CMV, } \\
\text { HIV, H1N1) }\end{array}$ & PKD, PNKD & $\begin{array}{l}\text { May have delay between injury and } \\
\text { presentation } \\
\text { Laboratory abnormalities; MRI brain may } \\
\text { be normal or with WM changes }\end{array}$ \\
\hline $\begin{array}{l}\text { Migraine } \\
\text { Autoimmune conditions } \\
\text { (SLE, APLS, Behçet's, anti- } \\
\text { VGKC, Hashimoto's, } \\
\text { paraneoplastic limbic } \\
\text { encephalitis, Celiac disease }\end{array}$ & PKD, PNKD, EA & $\begin{array}{l}\text { Systemic involvement, seizures, } \\
\text { encephalopathy, Autoantibodies, MRI } \\
\text { changes in WM or BG, mesial temporal } \\
\text { areas in limbic encephalitides }\end{array}$ \\
\hline $\begin{array}{l}\text { Metabolic disorders } \\
\text { hypo or hyperglycemia, } \\
\text { hypo/hyperparathyroidism, } \\
\text { hypocalcemia, }\end{array}$ & PKD, PNKD & $\begin{array}{l}\text { Presence of diabetes, thyroid or } \\
\text { parathyroid disease, laboratory } \\
\text { abnormalities in basic chemistry and/or } \\
\text { hormonal levels }\end{array}$ \\
\hline PNKD & PNon aural symptom, followed by \\
\hline
\end{tabular}




\begin{tabular}{|c|c|c|}
\hline thyrotoxicosis) & & \\
\hline $\begin{array}{l}\text { Basal ganglia calcifications } \\
\text { (with or without } \\
\text { hypocalcemia) }\end{array}$ & PKD, PNKD & $\begin{array}{l}\text { Calcifications on brain CT, hypointense on } \\
\text { T2 and hyperintense on T1 brain MRI; } \\
\text { occasionally laboratory abnormalities in } \\
\mathrm{Ca}, \mathrm{P} \text { and PTH levels }\end{array}$ \\
\hline $\begin{array}{l}\text { Other structural lesions in } \\
\text { the CNS (e.g., tumor, } \\
\text { meningioma, Chiari with } \\
\text { syringomyelia, etc.) }\end{array}$ & PKD, PNKD & $\begin{array}{l}\text { Baseline deficits or abnormal imaging in } \\
\text { neuroanatomically congruent area }\end{array}$ \\
\hline Methylphenidate treatment & PKD & Onset shortly after treatment initiation \\
\hline $\begin{array}{l}\text { Parkinsonism (Parkinson's } \\
\text { disease, PSP, vascular } \\
\text { Parkinsonism) }\end{array}$ & PKD, PED & $\begin{array}{l}\text { Late onset, clinical examination and } \\
\text { imaging }\end{array}$ \\
\hline Neuroacanthocytosis & PKD & Acanthocytes on blood smear \\
\hline \multicolumn{3}{|c|}{ 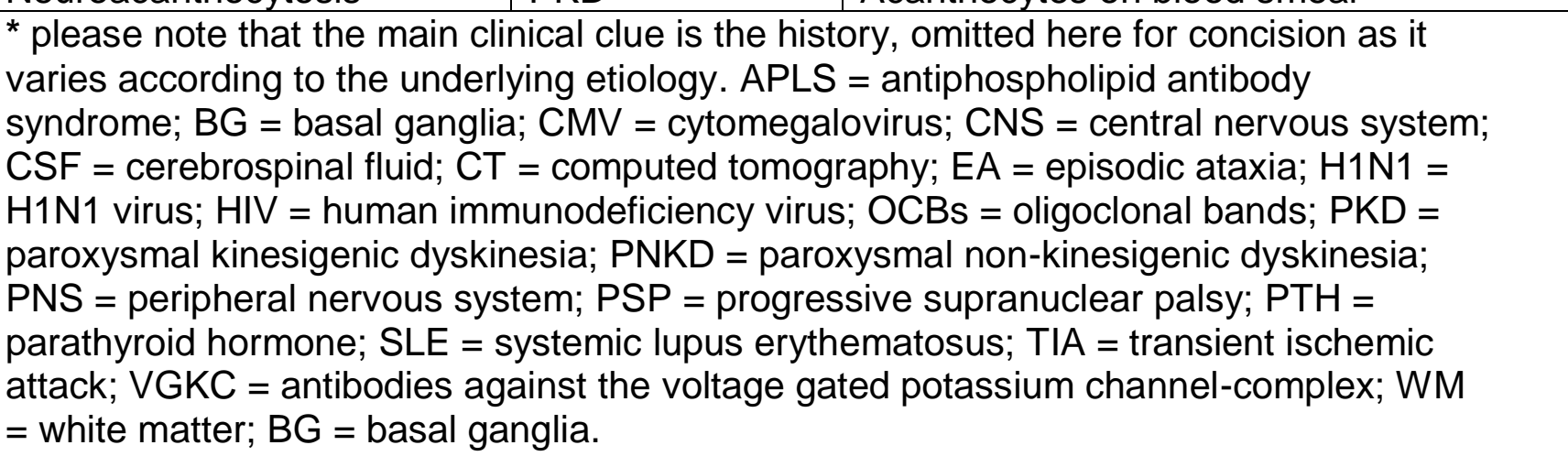 } \\
\hline
\end{tabular}

Table 6 - Diagnostic clues to psychogenic paroxysmal movement disorders (adapted from ref [154])

\begin{tabular}{|l|}
\hline Adult age of onset \\
\hline Variability in movement phenomenology, or paroxysmal tremor \\
\hline Variable and/or prolonged duration of attacks \\
\hline Odd triggers (i.e. during medical examination ) \\
\hline Unusual relieving maneuvers, including distractibility and entrainment \\
\hline Additional somatic or medically unexplained symptoms \\
\hline Multiple, inconsistent triggers \\
\hline Inconsistent or atypical response to medication \\
\hline
\end{tabular}




\section{References}

[1] Fahn S, Jankovic J, Hallett M. Principles and Practice of Movement Disorders. 2nd Editio. Philadelphia, PA: Elsevier; 2011.

[2] Kato N, Sadamatsu M, Kikuchi T, et al. Paroxysmal kinesigenic choreoathetosis: From first discovery in 1892 to genetic linkage with benign familial infantile convulsions. Epilepsy Res. 2006;70:174-184.

* this paper provides a historical review of the first descriptios of PKD to its recent genetic underpinnings

[3] Smith \&Na; Epilepsy and other Chronic Convulsive Diseases, Their Causes, Symptoms and Treatment. J. Nerv. Ment. Dis. 1902;29:185-186.

[4] Mount LA, Reback S. Familial paroxysmal choreoathetosis: Preliminary report on a hitherto undescribed clinical syndrome. Arch. Neurol. Psychiatry. 1940;44:841847.

*This is the first paper to report what was then known as Mount-Reback syndrome, currently termed PNKD

[5] Lance JW. Familial paroxysmal dystonic choreoathetosis and its differentiation from related syndromes. Ann. Neurol. 1977;2:285-293.

* Lance is credited being the first to describe paroxysmal exertional dyskinesia in this paper

[6] Goodenough DJ, Fariello RG, Annis BL, et al. Familial and Acquired Paroxysmal Dyskinesias: A Proposed Classification with Delineation of Clinical Features. Arch. Neurol. 1978;

[7] Fahn S. The paroxysmal dyskinesias. In: Marsden CD, Fahn S, editors. Mov. Disord. 3rd ed. Butterworth- Heinemann; 1994. p. 310-345.

[8] Lugaresi E, Cirignotta F. Hypnogenic paroxysmal dystonia: epileptic seizure or a new syndrome? Sleep. 1981;4:129-138.

* the first description of $P H D$

[9] Demirkiran M, Jankovic J. Paroxysmal Dyskinesias : Clinical Features and Classlfication. Ann. Neurol. 1995;38:571-579.

** this seminal paper proposed the classification of the paroxysmal dyskinesias based on inciting trigger that has proven quite useful and is used to this day.

[10] Lugaresi E, Cirignotta F, Montagna P. Nocturnal paroxysmal dystonia. J. Neurol. 
Neurosurg. Psychiatry. 1986;49:375-380.

[11] Provini F, Plazzi G, Lugaresi E. From nocturnal paroxysmal dystonia to nocturnal frontal lobe epilepsy. Clin. Neurophysiol. 2000;111 Suppl 2:S2-8.

* this paper reviews several cases of PHD and the discovery that they were epileptic in origin

[12] Parker HL. Periodic ataxia. Collect. Pap. Mayo Clin. Mayo Found. 1946;38:642645.

* Of historical value, this paper was the first to describe what is today known as episodic ataxia

[13] Klaas JP, Burkholder DB, Singer W, et al. Harry Lee Parker and paroxysmal dysarthria and ataxia. Neurology. 2013;80:311-314.

[14] Farmer TW, Mustian VM. Vestibulocerebellar Ataxia: A Newly Defined Hereditary Syndrome with Periodic Manifestations. Arch. Neurol. 1963;8:471-480.

[15] Hill W, Sherman H. Acute Intermittent Familial Cerebellar Ataxia. Arch. Neurol. 1968;18:350-357.

[16] White JC. Familial Periodic Nystagmus, Vertigo, and Ataxia. Arch. Neurol. 1969;20:276-280.

[17] Van Dyke DH, Griggs RC, Murphy MJ, et al. Hereditary myokymia and periodic ataxia. J. Neurol. Sci. 1975;25:109-118.

[18] Hanson PA, Martinez LB, Cassidy R. Contractures, continuous muscle discharges, and titubation. Ann. Neurol. 1977;120-124.

[19] Griggs RC, Moxley RT, Lafrance RA, et al. Hereditary paroxysmal ataxia: response to acetazolamide. Neurology. 1978;28:1259-1264.

[20] Donat JR, Auger R. Familial Periodic Ataxia. Arch. Neurol. 1979;36:568-569.

* this paper describes the serendipitous discovery of acetazolamide responsiveness in episodic ataxias

[21] Gancher ST, Nutt JG. Autosomal dominant episodic ataxia: A heterogeneous syndrome. Mov. Disord. 1986;1:239-253.

* this paper formed the basis for the phenotypic separation of the different episodic ataxias syndrome that we still use today 
[22] Bruno MK, Hallett M, Gwinn-Hardy K, et al. Clinical evaluation of idiopathic paroxysmal kinesigenic dyskinesia: new diagnostic criteria. Neurology. 2004;63:2280-2287.

** Bruno et al first proposed the diagnostic criteria for PKD in this now classic paper

[23] Méneret A, Gaudebout C, Riant F, et al. PRRT2 mutations and paroxysmal disorders. Eur. J. Neurol. 2013;20:872-878.

[24] Huang XJ, Wang T, Wang JL, et al. Paroxysmal kinesigenic dyskinesia. Clinical and genetic analysis of 110 patients. Neurology. 2015;85:1546-1553.

[25] Silveira-Moriyama L, Gardiner AR, Meyer E, et al. Clinical features of childhoodonset paroxysmal kinesigenic dyskinesia with PRRT2 gene mutations. Dev. Med. Child Neurol. 2013;55:327-334.

[26] Gardiner AR, Jaffer F, Dale RC, et al. The clinical and genetic heterogeneity of paroxysmal dyskinesias. Brain. 2015;138:3567-3580.

* In their extensive case review, the authors demonstrate the phenotypic overlap amongst carriers of pathogenic mutations in PRRT2, PNKD and SLC2A1

[27] Ebrahimi-Fakhari D, Saffari A, Westenberger A, et al. The evolving spectrum of PRRT2-associated paroxysmal diseases. Brain. 2015;138:3476-3495.

* this review paper highlighst the pleiotropic manifestations of pathogenic mutations in PRRT2

[28] Huang X-J, Wang T, Wang J-L, et al. Paroxysmal Kinesigenic Dyskinesia. Clinical and genetic analyses of 110 patients. Neurology. 2015;85:1546-1553.

[29] Seo SY, You SJ. Paroxysmal kinesigenic dyskinesia in a patient with a PRRT2 mutation and centrotemporal spike discharges on electroencephalogram: Case report of a 10-year-old girl. Korean J. Pediatr. 2016;59:S157-S160.

[30] El Achkar CM, Rosen Sheidley B, O'Rourke D, et al. Compound heterozygosity with PRRT2: Pushing the phenotypic envelope in genetic epilepsies. Epilepsy Behav. Case Reports. 2017;

[31] Wang JL, Cao L, Li XH, et al. Identification of PRRT2 as the causative gene of paroxysmal kinesigenic dyskinesias. Brain. 2011. p. 3490-3498.

[32] Chen W-J, Lin Y, Xiong Z-Q, et al. Exome sequencing identifies truncating mutations in PRRT2 that cause paroxysmal kinesigenic dyskinesia. Nat. Genet. 2011;43:1252-1255.

[33] Valtorta F, Benfenati F, Zara F, et al. PRRT2: from Paroxysmal Disorders to 
Regulation of Synaptic Function. Trends Neurosci. Elsevier Current Trends; 2016. p. 668-679.

[34] Ono S, Yoshiura K, Kinoshita A, et al. Mutations in PRRT2 responsible for paroxysmal kinesigenic dyskinesias also cause benign familial infantile convulsions. J. Hum. Genet. 2012;57:338-341.

[35] Dale RC, Gardiner A, Antony J, et al. Familial PRRT2 mutation with heterogeneous paroxysmal disorders including paroxysmal torticollis and hemiplegic migraine. Dev. Med. Child Neurol. 2012;54:958-960.

[36] Maini I, lodice A, Spagnoli C, et al. Expanding phenotype of PRRT2 gene mutations: A new case with epilepsy and benign myoclonus of early infancy. Eur. J. Paediatr. Neurol. 2016;20:454-456.

[37] Gardiner AR, Bhatia KP, Stamelou M, et al. PRRT2 gene mutations From paroxysmal dyskinesia to episodic ataxia and hemiplegic migraine. Neurology. 2012;

[38] Scheffer IE, Grinton BE, Heron SE, et al. PRRT2 phenotypic spectrum includes sporadic and fever-related infantile seizures. Neurology. 2012;

[39] Méneret A, Grabli D, Depienne C, et al. PRRT2 mutations : A major cause of paroxysmal kinesigenic dyskinesia in the European population. Neurology. 2012;79:170-174.

[40] Tian WT, Huang XJ, Mao X, et al. Proline-rich transmembrane protein 2-negative paroxysmal kinesigenic dyskinesia: Clinical and genetic analyses of 163 patients. Mov. Disord. 2018;33:459-467.

[41] Zima L, Ceulemans S, Reiner G, et al. Paroxysmal motor disorders: expanding phenotypes lead to coalescing genotypes. Ann. Clin. Transl. Neurol. 2018;5:9961010.

* Starting from a kindred with EA1, this paper provides extensive phenotypic documentation with videos for clinical clues in the diagnosis of this condition, and also provides a review with several genetic causes of paroxysmal movement disorders.

[42] Kim A, Jang M, Kim H-J, et al. Myotonia Congenita Can Be Mistaken as Paroxysmal Kinesigenic Dyskinesia. J. Mov. Disord. 2018;11:49-51.

[43] Wang HX, Li HF, Liu GL, et al. Mutation analysis of MR-1, SLC2A1, and CLCN1 in 28 PRRT2-negative paroxysmal kinesigenic dyskinesia patients. Chin. Med. J. (Engl). 2016;129:1017-1021.

[44] Bruno MK, Lee HY, Auburger GWJ, et al. Genotype-phenotype correlation of 
paroxysmal nonkinesigenic dyskinesia. Neurology. 2007;68:1782-1789.

** This paper lays out a proposed diagnostic criteria for PNKD-positive patients.

[45] Rainier S, Thomas D, Tokarz D, et al. Myofibrillogenesis Regulator 1 Gene Mutations Cause Paroxysmal Dystonic Choreoathetosis. Arch. Neurol. 2004;61:1025.

[46] Stefanova E, Djarmati A, Momcilovic D, et al. Clinical characteristics of paroxysmal nonkinesigenic dyskinesia in Serbian family with Myofibrillogenesis Regulator 1 gene mutation. Mov. Disord. 2006;21:2010-2015.

[47] Pons R, Cuenca-León E, Miravet E, et al. Paroxysmal non-kinesigenic dyskinesia due to a PNKD recurrent mutation: Report of two Southern European families. Eur. J. Paediatr. Neurol. 2012;16:86-89.

[48] Zittel S, Ganos C, Münchau A. Fatal paroxysmal non-kinesigenic dyskinesia. Eur. J. Neurol. 2015;22:e30-e31.

[49] Zhang Z-B, Tian M-Q, Gao K, et al. De novo KCNMA1 mutations in children with early-onset paroxysmal dyskinesia and developmental delay. Mov. Disord. $2015 ; 30: 1290-1292$.

[50] McWilliam CA, Ridout CK, Brown RM, et al. Pyruvate dehydrogenase E2 deficiency: a potentially treatable cause of episodic dystonia. Eur. J. Paediatr. Neurol. 2010;14:349-353.

[51] Odièvre $\mathrm{M}-\mathrm{H}$, Chretien $\mathrm{D}$, Munnich $\mathrm{A}$, et al. A novel mutation in the dihydrolipoamide dehydrogenase E3 subunit gene (DLD) resulting in an atypical form of $\alpha$-ketoglutarate dehydrogenase deficiency. Hum. Mutat. 2005;25:323-324.

[52] BARNERIAS C, SAUDUBRAY J-M, TOUATI G, et al. Pyruvate dehydrogenase complex deficiency: four neurological phenotypes with differing pathogenesis. Dev. Med. Child Neurol. 2010;52:e1-e9.

[53] Plant GT, Williams AC, Earl CJ, et al. Familial paroxysmal dystonia induced by exercise. J. Neurol. Neurosurg. Psychiatry. 1984;47:275-279.

[54] Lees AJ, Hardie RJ, Stern GM. Kinesigenic foot dystonia as a presenting feature of Parkinson's disease. J. Neurol. Neurosurg. Psychiatry. 1984;47:885.

[55] Bozi M, Bhatia KP. Paroxysmal exercise-induced dystonia as a presenting feature of young-onset Parkinson's disease. Mov. Disord. 2003;18:1545-1547.

[56] Clark CN, Weber YW, Lerche $\mathrm{H}$, et al. Paroxysmal exercise-induced dyskinesia of the hands. Mov. Disord. 2012;27:1579-1580. 
[57] Pearson TS, Akman C, Hinton VJ, et al. Phenotypic Spectrum of Glucose Transporter Type 1 Deficiency Syndrome (Glut1 DS). Curr. Neurol. Neurosci. Rep. 2013;13:342.

[58] Dale RC, Melchers A, Fung VS, et al. Familial paroxysmal exercise-induced dystonia: Atypical presentation of autosomal dominant GTP-cyclohydrolase 1 deficiency. Dev. Med. Child Neurol. 2010;52:583-586.

[59] Lohmann E, Periquet M, Bonifati V, et al. How much phenotypic variation can be attributed to parkin genotype? Ann. Neurol. 2003;54:176-185.

[60] Yoshimura K, Kanki R. Child-onset paroxysmal exercise-induced dystonia as the initial manifestation of hereditary Parkinson's disease. Park. Relat. Disord. 2018;49:108-109.

[61] Ogawa $\mathrm{Y}$, Nakamura K, Ezawa N, et al. A novel CACNA1A nonsense variant in a patient presenting with paroxysmal exertion-induced dyskinesia. J. Neurol. Sci. 2019;399:214-216.

[62] Mahajan A, Constantinou J, Sidiropoulos C. ECHS1 deficiency-associated paroxysmal exercise-induced dyskinesias: case presentation and initial benefit of intervention. J. Neurol. 2017;264:185-187.

[63] Mongin M, Mezouar N, Dodet P, et al. Paroxysmal Exercise-induced Dyskinesias Caused by GLUT1 Deficiency Syndrome. Tremor Other Hyperkinet. Mov. (N. Y). 2016;6:371.

[64] Klepper J, Leiendecker B, Eltze C, et al. Paroxysmal Nonepileptic Events in Glut1 Deficiency. Mov. Disord. Clin. Pract. 2016;3:607-610.

* This paper provides clinical information and videos on the different motor manifestations of patients with SLC2A1 mutations

[65] Urbizu A, Cuenca-León E, Raspall-Chaure M, et al. Paroxysmal exercise-induced dyskinesia, writer's cramp, migraine with aura and absence epilepsy in twin brothers with a novel SLC2A1 missense mutation. J. Neurol. Sci. 2010;295:110113.

[66] Ramm-Pettersen A, Nakken KO, Haavardsholm KC, et al. GLUT1-deficiency syndrome: Report of a four-generation Norwegian family with a mild phenotype. Epilepsy Behav. 2017;70:1-4.

[67] Roubergue A, Apartis E, Mesnage V, et al. Dystonic tremor caused by mutation of the glucose transporter gene GLUT1. J. Inherit. Metab. Dis. 2011;34:483-488.

[68] Zorzi G, Castelloti B, Zibordi F, et al. Paroxysmal movement disorders in Glut 1 deficiency syndrome. Neurology. 2008;71:146-148. 
* One of the earliest papers describing the paroxysmal nature of events associated with SLC2A1 mutations

[69] Tacik P, Loens S, Schrader C, et al. Severe familial paroxysmal exercise-induced dyskinesia. J. Neurol. 2014;261:2009-2015.

[70] Ogunyemi AO, Gomez MR, Klass DW. Seizures induced by exercise. Neurology. 1998;38:633-634.

[71] Tinuper P, Bisulli F, Provini F, et al. Familial frontal lobe epilepsy and its relationship with other nocturnal paroxysmal events. Epilepsia. 2010;51:51-53.

[72] Heron SE, Smith KR, Bahlo M, et al. Missense mutations in the sodium-gated potassium channel gene KCNT1 cause severe autosomal dominant nocturnal frontal lobe epilepsy. Nat. Genet. 2012;44:1188-1190.

[73] Dibbens LM, de Vries B, Donatello S, et al. Mutations in DEPDC5 cause familial focal epilepsy with variable foci. Nat. Genet. 2013;45:546-551.

[74] Tinuper P, Bisulli F. From nocturnal frontal lobe epilepsy to Sleep-Related Hypermotor Epilepsy: A 35-year diagnostic challenge. Seizure. 2017;44:87-92.

[75] Lee BI, Lesser RP, Pippenger CE, et al. Familial Paroxysmal hypnogenic dystonia. Neurology. 1985;35:1357-1360.

[76] Liu X-R, Huang D, Wang J, et al. Paroxysmal hypnogenic dyskinesia is associated with mutations in the PRRT2 gene. Neurol. Genet. 2016;2:e66.

[77] Chen Y-Z, Friedman JR, Chen D-H, et al. Gain-of-function ADCY5 mutations in familial dyskinesia with facial myokymia. Ann. Neurol. 2014;75:542-549.

[78] Friedman JR, Méneret A, Chen D-H, et al. ADCY5 mutation carriers display pleiotropic paroxysmal day and nighttime dyskinesias. Mov. Disord. 2016;31:147148.

${ }^{*}$ Rich clinical and video documentation of the varied features of ADCY5 mutations

[79] Carecchio M, Mencacci NE, lodice A, et al. ADCY5-related movement disorders: Frequency, disease course and phenotypic variability in a cohort of paediatric patients. Park. Relat. Disord. 2017;41:37-43.

[80] Provini F, Plazzi G, Montagna P, et al. The wide clinical spectrum of nocturnal frontal lobe epilepsy. Sleep Med. Rev. 2000;4:375-386.

[81] Browne DL, Gancher ST, Nutt JG, et al. Episodic ataxia/myokymia syndrome is associated with point mutations in the human potassium channel gene, KCNA1. Nat. Genet. 1994;8:136-140. 
[82] Graves TD, Cha Y-H, Hahn AF, et al. Episodic ataxia type 1: clinical characterization, quality of life and genotype-phenotype correlation. Brain. 2014;137:1009-1018.

** In an innovative approach, the authors used a automated phone call system to record real-world prospective clinical data in a cohort of patients with episodic ataxia type 1 ,providing several clinical insights, in the first study of its kind in this group of disorders.

[83] Jen JC, Graves TD, Hess EJ, et al. Primary episodic ataxias: Diagnosis, pathogenesis and treatment. Brain. 2007;130:2484-2493.

[84] Kipfer S, Strupp M. The Clinical Spectrum of Autosomal-Dominant Episodic Ataxias. Mov. Disord. Clin. Pract. 2014;1:285-290.

[85] Lee $\mathrm{H}$, Wang $\mathrm{H}$, Jen JC, et al. A novel mutation in KCNA1 causes episodic ataxia without myokymia. Hum. Mutat. 2004;24:1-7.

[86] Shook SJ, Mamsa H, Jen JC, et al. Novel mutation in KCNA1 causes episodic ataxia with paroxysmal dyspnea. Muscle and Nerve. 2008;37:399-402.

[87] Eunson LH, Rea R, Zuberi SM, et al. Clinical, genetic, and expression studies of mutations in the potassium channel gene KCNA1 reveal new phenotypic variability. Ann. Neurol. 2000;48:647-656.

[88] Klein A, Boltshauser E, Jen J, et al. Episodic ataxia type 1 with distal weakness: a novel manifestation of a potassium channelopathy. Neuropediatrics. 2004;35:147-149.

[89] Glaudemans B, van der Wijst J, Scola $\mathrm{RH}$, et al. A missense mutation in the Kv1.1 voltage-gated potassium channel-encoding gene KCNA1 is linked to human autosomal dominant hypomagnesemia. J. Clin. Invest. 2009;119:936-942.

[90] van der Wijst J, Konrad M, Verkaart SAJ, et al. A de novo KCNA1 Mutation in a Patient with Tetany and Hypomagnesemia. Nephron. 2018;139:359-366.

[91] Baloh RW. Episodic ataxias 1 and 2. Handb. Clin. Neurol. 2012;103:595-602.

[92] Brederlow B Von, Hahn AF, Koopman WJ, et al. Mapping the gene for acetazolamide responsive hereditary paryoxysmal cerebellar ataxia to chromosome 19p. Hum. Mol. Genet. 1995;4:279-284.

[93] Vahedi K, Joutel A, van Bogaert $P$, et al. A gene for hereditary paroxysmal cerebellar ataxia maps to chromosome 19p. Ann. Neurol. 1995;37:289-293.

[94] Ophoff RA, Terwindt GM, Vergouwe MN, et al. Familial hemiplegic migraine and episodic ataxia type-2 are caused by mutations in the $\mathrm{Ca} 2+$ channel gene 
CACNL1A4. Cell. 1996;87:543-552.

[95] Griggs RC, Nutt JG. Episodic ataxias as channelopathies. Ann. Neurol. 1995;37:285-287.

[96] Zhou L, Zhang CL, Messing A, et al. Temperature-sensitive neuromuscular transmission in Kv1.1 null mice: role of potassium channels under the myelin sheath in young nerves. J. Neurosci. 1998;18:7200-7215.

[97] Mori Y, Friedrich T, Kim M-S, et al. Primary structure and functional expression from complementary DNA of a brain calcium channel. Nature. 1991;350:398-402.

[98] Zhuchenko O, Bailey J, Bonnen P, et al. Autosomal dominant cerebellar ataxia (SCA6) associated with small polyglutamine expansion in the a1A-voltagedependent calcium channel. Nat. Genet. 1997;15:62-69.

[99] Bürk K, Kaiser FJ, Tennstedt S, et al. A novel missense mutation in CACNA1A evaluated by in silico protein modeling is associated with non-episodic spinocerebellar ataxia with slow progression. Eur. J. Med. Genet. 2014;57:207211.

[100] Jen J, Wan J, Graves M, et al. Loss-of-function EA2 mutations are associated with impaired neuromuscular transmission. Neurology. 2001;57:1843-1848.

[101] Jouvenceau A, Eunson LH, Spauschus A, et al. Human epilepsy associated with dysfunction of the brain P/Q-type calcium channel. Lancet. 2001;358:801-807.

[102] Spacey SD, Materek LA, Szczygielski BI, et al. Two novel CACNA1A gene mutations associated with episodic ataxia type 2 and interictal dystonia. Arch. Neurol. 2005;62:314-316.

[103] Subramony SH, Schott K, Raike RS, et al. Novel CACNA1A Mutation Causes Febrile Episodic Ataxia with Interictal Cerebellar Deficits. Ann. Neurol. 2003;54:725-731.

[104] Baloh RW, Yue Q, Furman JM, et al. Familial episodic ataxia: Clinical heterogeneity in four families linked to chromosome 19p. Ann. Neurol. 1997;41:816.

[105] Jen J, Kim GW, Baloh RW. Clinical spectrum of episodic ataxia type 2. Neurology. 2004;62:17-22.

* A comprehensive review of a cohort of patients with EA2

[106] Bertholon P, Chabrier S, Riant F, et al. Episodic ataxia type 2: unusual aspects in clinical and genetic presentation. Special emphasis in childhood. J. Neurol. Neurosurg. Psychiatry. 2009;80:1289-1292. 
[107] Giffin NJ, Benton S, Goadsby PJ. Benign paroxysmal torticollis of infancy: four new cases and linkage to CACNA1A muta1. Giffin NJ, Benton S, Goadsby PJ. Benign paroxysmal torticollis of infancy: four new cases and linkage to CACNA1A mutation. Dev Med Child Neurol. 2002;44(7):490-3. tion. Dev. Med. Child Neurol. 2002;44:490-493.

[108] Roubertie A, Echenne B, Leydet J, et al. Benign paroxysmal tonic upgaze, benign paroxysmal torticollis, episodic ataxia and CACNA1A mutation in a family. J. Neurol. 2008;255:1600-1602.

[109] Mantuano E, Romano S, Veneziano L, et al. Identification of novel and recurrent CACNA1A gene mutations in fifteen patients with episodic ataxia type 2. J. Neurol. Sci. 2010;291:30-36.

[110] Harries AM, Sandhu M, Spacey SD, et al. Unilateral pallidal deep brain stimulation in a patient with dystonia secondary to episodic ataxia type 2. Stereotact. Funct. Neurosurg. 2013;91:233-235.

[111] Jen JC, Wan J. Episodic ataxias. Handb. Clin. Neurol. Elsevier; 2018. p. 205-215. ${ }^{*} A$ recent review on the subject

[112] Steckley JL, Ebers GC, Cader MZ, et al. An autosomal dominant disorder with episodic ataxia, vertigo, and tinnitus. Neurology. 2001;57:1499-1502.

[113] Cader MZ, Steckley JL, Dyment DA, et al. A genome-wide screen and linkage mapping for a large pedigree with episodic ataxia. Neurology. 2005;65:156-158.

[114] Damji KF, Allingham RR, Pollock SC, et al. Periodic vestibulocerebellar ataxia, an autosomal dominant ataxia with defective smooth pursuit, is genetically distinct from other autosomal dominant ataxias. Arch. Neurol. 1996;53:338-344.

[115] Escayg A, De Waard M, Lee DD, et al. Coding and Noncoding Variation of the Human Calcium-Channel $\beta 4-S u b u n i t$ Gene CACNB4 in Patients with Idiopathic Generalized Epilepsy and Episodic Ataxia. Am. J. Hum. Genet. 2000;66:15311539.

[116] de Vries B, Mamsa H, Stam AH, et al. Episodic Ataxia Associated With EAAT1 Mutation C186S Affecting Glutamate Reuptake. Arch. Neurol. 2009;66:97-101.

[117] Choi K-D, Jen JC, Choi SY, et al. Late-onset episodic ataxia associated with SLC1A3 mutation. J. Hum. Genet. 2017;62:443-446.

[118] Jen JC, Wan J, Palos TP, et al. Mutation in the glutamate transporter EAAT1 causes episodic ataxia, hemiplegia, and seizures. Neurology. 2005;65:529-534. 
[119] Adamczyk A, Gause CD, Sattler R, et al. Genetic and functional studies of a missense variant in a glutamate transporter, SLC1A3, in Tourette syndrome. Psychiatr. Genet. 2011;21:90-97.

[120] van Amen-Hellebrekers CJM, Jansen S, Pfundt R, et al. Duplications of SLC1A3: Associated with ADHD and autism. Eur. J. Med. Genet. 2016;59:373-376.

[121] Kerber KA, Jen JC, Lee $\mathrm{H}$, et al. A new episodic ataxia syndrome with linkage to chromosome 19q13. Arch. Neurol. 2007;64:749-752.

[122] Conroy J, McGettigan P, Murphy R, et al. A novel locus for episodic ataxia: UBR4 the likely candidate. Eur. J. Hum. Genet. 2014;22:505-510.

[123] Blakeley J, Jankovic J. Secondary paroxysmal dyskinesias. Mov. Disord. 2002;17:726-734.

** The most comprehensive study of its kind so far, the authors describe a cohort of patients with secondary paroxysmal dyskinesias and helpful clinical features to help discern cases from primary etiologies.

[124] Erro R, Stamelou M, Ganos C, et al. The Clinical Syndrome of Paroxysmal Exercise-Induced Dystonia: Diagnostic Outcomes and an Algorithm. Mov. Disord. Clin. Pract. 2014;1:57-61.

[125] Leen WG, Wevers RA, Kamsteeg E-J, et al. Cerebrospinal Fluid Analysis in the Workup of GLUT1 Deficiency Syndrome. JAMA Neurol. 2013;70:1440.

[126] Silveira-Moriyama L, Paciorkowski AR. Genetic Diagnostics for Neurologists. Contin. Lifelong Learn. Neurol. 2018;24:18-36.

[127] Wang D, Pascual JM, De Vivo D. Glucose Transporter Type 1 Deficiency Syndrome. GeneReviews ${ }^{\circledR}$. University of Washington, Seattle; 1993.

[128] Jodice C, Mantuano E, Veneziano L, et al. Episodic ataxia type 2 (EA2) and spinocerebellar ataxia type 6 (SCA6) due to CAG repeat expansion in the CACNA1A gene on chromosome 19p. Hum. Mol. Genet. 1997;6:1973-1978.

[129] Silveira-Moriyama L, Kovac S, Kurian MA, et al. Phenotypes, genotypes , and the management of paroxysmal movement disorders. Dev. Med. Child Neurol. 2018;60:559-566.

[130] Erro R, Bhatia KP, Espay AJ, et al. The epileptic and nonepileptic spectrum of paroxysmal dyskinesias: Channelopathies, synaptopathies, and transportopathies. Mov. Disord. 2017;32:310-318.

[131] Kertesz A. Paroxysmal kinesigenic choreoathetosis. 1967;17. 
[132] Loong S, Ong Y. Paroxysmal kinesigenic choreoathetosis Report of a case relieved by L-dopa. J. Neurol. Neurosurg. Psychiatry. 1973;36:921-924.

[133] Merlis S. Diamox: A Carbonic Anhydrase Inhibitor: Its Use in Epilepsy. Neurology. 1954;4:863-863.

[134] Resnick JS, Engel WK, Griggs RC, et al. Acetazolamide Prophylaxis in Hypokalemic Periodic Paralysis. N. Engl. J. Med. 1968;278:582-586.

[135] Strupp M, Kalla R, Claassen J, et al. A randomized trial of 4-aminopyridine in EA2 and related familial episodic ataxias. Neurology. 2011;77:269-275.

* the only randomized interventional trial in this group of disorders where management remains largely empirical

[136] Baschieri F, Batla A, Erro R, et al. Paroxysmal exercise-induced dystonia due to GLUT1 mutation can be responsive to levodopa: a case report. J. Neurol. 2014;261:615-616.

[137] Labate A, Tarantino P, Viri M, et al. Homozygous c.649dupC mutation in PRRT2 worsens the BFIS/PKD phenotype with mental retardation, episodic ataxia, and absences. Epilepsia. 2012;53:e196-e199.

[138] Amstutz U, Shear NH, Rieder MJ, et al. Recommendations for HLA-B*15:02 and HLA-A*31:01 genetic testing to reduce the risk of carbamazepine-induced hypersensitivity reactions. Epilepsia. 2014;55:496-506.

[139] Plumpton CO, Yip VLM, Alfirevic A, et al. Cost-effectiveness of screening for HLA$A * 31: 01$ prior to initiation of carbamazepine in epilepsy. Epilepsia. 2015;56:556563.

[140] Tangamornsuksan W, Chaiyakunapruk N, Somkrua R, et al. Relationship between the HLA-B* 1502 allele and carbamazepine-induced Stevens-Johnson syndrome and toxic epidermal necrolysis: a systematic review and meta-analysis. JAMA dermatology. 2013;149:1025-1032.

[141] Li F, Lin Z, Hu Y, et al. Lamotrigine monotherapy for paroxysmal kinesigenic dyskinesia in children. Seizure. 2016;37:41-44.

[142] Erro R. Familial Paroxysmal Nonkinesigenic Dyskinesia. GeneReviews ${ }^{\circledR}$. University of Washington, Seattle; 1993.

[143] Szczałuba K, Jurek M, Szczepanik E, et al. A Family With Paroxysmal Nonkinesigenic Dyskinesia: Genetic and Treatment Issues. Pediatr. Neurol. 2009;41:135-138. 
[144] Coller R Van, Slabbert P, Vaidyanathan J, et al. Successful treatment of disabling paroxysmal nonkinesigenic dyskinesia with deep brain stimulation of the globus pallidus internus. Stereotact. Funct. Neurosurg. 2014;92:388-392.

[145] Leen WG, Mewasingh L, Verbeek MM, et al. Movement disorders in GLUT1 deficiency syndrome respond to the modified Atkins diet. Mov. Disord. 2013;28:1439-1442.

[146] Mochel F, Hainque E, Gras D, et al. Triheptanoin dramatically reduces paroxysmal motor disorder in patients with GLUT1 deficiency. J. Neurol. Neurosurg. Psychiatry. 2016;87:550-553.

[147] Hainque E, Gras D, Meneret A, et al. Long-term follow-up in an open-label trial of triheptanoin in GLUT1 deficiency syndrome: a sustained dramatic effect. J. Neurol. Neurosurg. Psychiatry. 2019;jnnp-2018-320283.

[148] Anheim M, Maillart E, Vuillaumier-Barrot S, et al. Excellent response to acetazolamide in a case of paroxysmal dyskinesias due to GLUT1-deficiency. J. Neurol. 2011;258:316-317.

[149] Guimarães J, Vale Santos J. Paroxysmal dystonia induced by exercise and acetazolamide. Eur. J. Neurol. 2000;7:237-240.

[150] Bovi T, Fasano A, Juergenson I, et al. Paroxysmal exercise-induced dyskinesia with self-limiting partial epilepsy: A novel GLUT-1 mutation with benign phenotype. Parkinsonism Relat. Disord. 2011;17:479-481.

[151] Sethi KD, Hess DC, Huffnagle VH, et al. Acetazolamide treatment of paroxysmal dystonia in central demyelinating disease. Neurology. 1992;42:919-921.

[152] Choi K-D, Choi J-H. Episodic Ataxias: Clinical and Genetic Features. J. Mov. Disord. 2016;9:129-135.

[153] Roze E, Meneret A, Vidailhet M. Paroxysmal Movement Disorders: Clinical and Genetic features. In: LeDoux MS, editor. Mov. Disord. Genet. Model. 2nd ed. Elsevier; 2015. p. 767-778.

[154] Ganos C, Aguirregomozcorta M, Batla A, et al. Psychogenic paroxysmal movement disorders - Clinical features anddiagnostic clues. Park. Relat. Disord. 2014;20:41-46.

${ }^{* *}$ Helpful clinical clues to differentiate functional dyskinesias from genetically mediated or secondary causes. 